DOI: $10.17805 / z p u .2015 .2 .10$

\title{
Социальные риски пожилых россиян, не получающих социальные услуги на дому
}

\author{
М. Г. СОЛНЫШКИНА, О. А. ТЮКИН \\ (МОСКОВСКИЙ ГУМАНИТАРНЫЙ УНИВЕРСИТЕТ)
}

На социальном фоне сложной медико-демографической ситуации старения населения, роста потребности в социальных услугах имеется социальная категория пожилых людей, «латентная» и невидимая для современной системы социального обслуживания на институциональном уровне. Ее составляют пожилые россияне, информация о проблемах, образе и качестве жизни которых явно недостаточна для соблюдения прав и обеспечения социальной безопасности.

Проблема совершенствования социального обслуживания пожилых в условиях общества риска является актуальной как для современного социологического знания, так и для системы социальной работы. В рискологической концепции качества жизни (Г. П. Петропавлова, Е. В. Шлыкова, Е. В. Щекотин) сформировался комплексный подход, включающий риски, угрозы и опасности при оценке качества жизни как характеристики условий человеческой деятельности.

В рамках научной школы исследователей кафедр социологии, социальной работы и социальной медицины Московского гуманитарного университета (В. В. Колков, В. В. Соколова, Е. А. Воробцова, С. П. Бурцев) для выявления социальных рисков пожилых людей, не получающих социальные услуги на дому, в 2014 - начале 2015 г. проведено социологическое исследование. Респонденты - 150 человек (65\% женщин и 35\% мужчин в возрасте от 64 до 80 лет), жители Московской области. Исследование социальных рисков пожилых проводилось с помощью метода анкетирования.

Исследование показало, что наиболее распространенными рисками для пожилых россиян, не получающих социальные услуги на дому, являются риски мошенничества, материального неблагополучия и ухудшения здоровья. В структуре рисков пожилых людей присутствуют также риски утраты родственных связей, социальной изолированности 
и деформации поведения. Выявлены институциональные препятствия, снижающие востребованность надомного социального обслуживания как инструмента минимизации социальных рисков пожилых.

Ключевые слова: социальные риски, социальная защита, социальное обслуживание на дому, социальное обеспечение, пожилые люди, качество жизни.

\section{ВВЕАЕНИЕ}

$\mathrm{B}$ глобальном пространстве качества жизни пожилых, по результатам исследований Международной неправительственной организации HelpAge International coвместно с Фондом Организации Объединенных Наций в области народонаселения (ЮНФПА) в 2014 г., индекс качества жизни и благополучия пожилых россиян находился на 65-м месте и располагался между Беларусью и Парагваем (HelpAge International ..., 2013). Оценивание по 13 показателям показало крайне низкий уровень вовлеченности старшего поколения России в общественную жизнь, плохое состояние здоровья, низкий уровень материального обеспечения, неблагоприятность среды для пожилых в целом (Гоман, 2012). Особую категорию пожилых людей составляют не получающие социальные услуги на дому и не обращающиеся в органы социальной поддержки для получения помощи. Информация об их проблемах, образе и качестве жизни явно недостаточна, во многом данная социальная категория является «латентной» и невидимой для современной системы социального обслуживания, что потенциально увеличивает вероятность социальных рисков (Климантова, Черняк, Щегорцов, 2014). Особое беспокойство вызывает положение маломобильных пожилых (количество которых достигает 50\% после 75 лет), имеющих низкую социальную активность и меньше возможностей для решения жизненных проблем, что потенциально увеличивает вероятность социальных рисков (Социальная работа ..., 1995). Вышеперечисленные факторы как на уровне российского, так и на уровне глобального пространства актуализируют проблему исследования жизненных проблем и социальных рисков пожилых людей, не получающих социальные услуги в государственной системе надомного социального обслуживания.

\section{СОЦИААЬНОЕ ОБСАУЖИВАНИЕ \\ И СОЦИААЬНЫЕ РИСКИ ПОЖИАЫХ}

Социальное обслуживание является важнейшим институтом, обеспечивающим поддержание достойного уровня качества жизни населения. Под социальным обслуживанием понимается деятельность по предоставлению социальных услуг. Обслуживание осуществляется путем предоставления гражданам, нуждающимся в постоянном или временном нестационарном социальном обслуживании, частично утратившим способность к самообслуживанию, помощи на дому в виде социальнобытовых, социально-медицинских услуг и иной помощи (Солнышкина, 2005). Надомное социальное обслуживание как стационарозамещающая форма помощи обеспечивает максимальное приближение социальных услуг к месту проживания клиента, реализацию принципа адресности и доступности услуг для маломобильных граждан. С вступлением в силу Федерального закона от 28 декабря 2013 г. № 442-Ф3 «Об основах социального обслуживания граждан в Российской Федерации» (Федеральный закон ... : Электр. ресурс) оказание социальных услуг сможет осуществляться не только государственными органами, но и коммерческими организациями. Предполагается, что введение закона обеспечит повышение качества социальных услуг (Колков, 2011). 
В России постоянно увеличивается количество пожилых граждан с ограничениями самостоятельного передвижения. Результаты исследований показывают, что около $50 \%$ пожилых людей испытывают существенные затруднения при ходьбе и подъеме по лестнице, до 41\% пожилых людей не могут самостоятельно посещать медицинские учреждения. Явным ограничением мобильности страдают около $15 \%$ лиц в возрасте 65-74 лет, причем после 75 лет эта цифра возрастает до 30\%; 8\% не покидают своей квартиры, а 5\% - даже своей постели. В целом затруднения при самообслуживании испытывают 31\% пожилых людей России (Золотарева, 2010).

Суть рискологического подхода состоит в том, что, оценивая качество жизни, необходимо учитывать риски, угрозы и опасности, характеризующие условия человеческой жизнедеятельности, реализация которых может привести к неблагоприятным последствиям для человека (Шлыкова, 2001). Потери и проблемы рассматривают в терминах рисков, возникающих в процессе функционирования человека в обществе. Потери у пожилых людей могут быть в виде ущерба здоровью и жизни, прямых и косвенных экономических потерь. С позиций рискологической теории качества жизни «совокупный риск напрямую определяет качество жизни, он характеризует степень защищенности/безопасности человека в обществе» (Щекотин, 2011: 69). Качество жизни с изложенных позиций выступает как функция различных типов рисков, следовательно, повышение качества жизни надо рассматривать как результат снижения совокупности рисков.

Е. Н. Касаркина и Ю. А. Тузова выделяют две группы факторов, способствующих возникновению социальных рисков пожилых людей: 1) объективные факторы - общее социально-экономическое развитие государства, система социальной защиты, характер материальных и хозяйственных взаимоотношений, социальные нормы, общественные потребности и ожидания, условия проживания; 2) субъективные факторы: структура семьи пожилого человека, супружество, наличие или отсутствие детей, роль пожилого человека в семье, уровень образования, пол, возраст (Касаркина, Тузова, 2013).

\section{ИССАЕАОВАНИЕ СОЦИААЬНЫХ РИСКОВ ПОЖИАЫХ, НЕ ПОАУЧАЮЩИХ СОЦИААЬНЫЕ УСАУГИ НА АОМУ}

Аля выявления социальных рисков пожилых людей, не получающих социальные услуги на дому, проведено социологическое исследование. Респондентами стали 150 человек, проживающих в Московской области, из них $65 \%$ женщин и $35 \%$ мужчин в возрасте от 64 до 80 лет.

Объект исследования: пожилые люди, не получающие социальные услуги на дому.

Предмет исследования: жизненные проблемы и социальные риски пожилых, не получающих социальные услуги на дому.

Исследование социальных рисков пожилых проводилось с помощью метода анкетирования в период с октября 2014 по январь 2015 г. по следующим индикаторам и показателям:

- наличие и содержание жизненных проблем;

- возможность их самостоятельного решения;

- причины необращения в органы социального обслуживания;

- социальные риски пожилых, не получающих социальные услуги (их структура и частота проявления).

В рамках исследования использована классификация социальных рисков пожилых людей, разработанная М. В. Корниловой. Она выделяет следующие виды социальных рисков: 
- бедность и материальное неблагополучие (по сравнению с гражданами трудоспособного возраста пожилые люди имеют ограниченные физические и адаптационные возможности, препятствующие самообеспечению);

- ухудшение здоровья (старение человека сопровождается неуклонным увеличением риска возникновения заболеваний);

- социальная изолированность (пожилые люди часто становятся ненужными обществу в силу того, что они не участвуют в социальных процессах);

- утрата родственных связей (потеря родственных связей, ненужность пожилого человека его близким из-за болезни и других причин);

- деформация норм поведения (жизненные проблемы и трудности становятся факторами деформации поведения пожилого человека - замкнутости, агрессивности, девиаций);

- риск мошенничества (чрезмерная доверчивость пожилых людей провоцирует действия мошенников) (Корнилова, 2011).

Установление наличия и степени выраженности социальных рисков пожилых людей предполагает необходимость анализа их жизненных проблем как угроз и опасностей, которые дифференцировались в соответствии с классификацией социальных рисков и объединялись в соответствующие группы: риски ухудшения здоровья; бедности и материального неблагополучия; социальной изолированности, деформации норм поведения; мошенничества и противоправных действий. Одновременно жизненные проблемы рассматривались нами как важнейшие индикаторы качества жизни.

Анкетирование позволило установить, что проблемы пожилых людей связаны преимущественно со здоровьем (78\%), материальными нуждами $(45,5 \%)$, организацией и обеспечением питания (36,3\%) и трудовой деятельностью $(28,7 \%)$. Субъективная оценка уровня здоровья пожилых людей в основном находится на удовлетворительном $(52 \%)$ и низком $(21,6 \%)$ уровнях. $40 \%$ опрошенных недовольны оказываемой им медицинской помощью. Треть пожилых людей, принявших участие в анкетировании $(33,1 \%)$, не имеют материальной возможности для приобретения необходимых лекарственных средств и могут позволить себе только покупку продуктов питания, покупка более дорогих предметов (одежды, мебели, техники) им недоступна.

Важной частью исследования стало выявление степени мобильности респондентов как потенциальной возможности самостоятельного решения проблем. Результаты проведенного анкетирования свидетельствуют о том, что треть респондентов $(31,3 \%)$ имеют недостаточную мобильность и не могут посещать различные учреждения, организации и другие общественные места, что обусловливает объективную необходимость получения социальных услуг на дому. В связи с этим целесообразно выявление причин, по которым пожилые люди не обращаются в органы социальной защиты для получения социальных услуг. В данном аспекте результаты исследования показали, что 39,8\% надеются на помощь родственников; 28,5\% сомневаются в том, что органы социальной защиты способны оказать продуктивную поддержку; 22,7\% не считают нужным получать от кого-либо помощь и желают справляться со своими проблемами самостоятельно; 9\% опрошенных не знают, как получить социальные услуги на дому.

Таким образом, основными причинами необращения в органы социального обслуживания для получения социальных услуг на дому являются незнание своих социальных прав и порядка получения услуг, восприятие данной процедуры как совокупности сложных административных барьеров (множество справок, очередей, потеря 
времени), сомнение в эффективности социальных услуг и их способности оказать действенную помощь пожилому человеку, надежда на помощь родственников (Холостова, 2013).

На институциональном уровне результаты исследования свидетельствуют о том, что развитию надомного социального обслуживания препятствует наличие двух существенных проблем. Первая проблема заключается в том, что практически треть пожилых людей, вынужденных постоянно оставаться дома, не верят в эффективность социального обслуживания на дому. Они считают, что помощь социальных работников не окажется продуктивной, что свидетельствует о недоверии и негативном восприятии института социальной поддержки (Тимошина, 2012). Мы считаем, что подобное восприятие основано не столько на стереотипах, сколько на качестве государственных социальных услуг, которое, по мнению многих граждан, находится на недостаточном уровне. Об этом свидетельствуют и следующие результаты анкетирования: $28 \%$ опрошенных считают, что обращение в социальные органы не помогает пожилым людям, получающим социальные услуги на дому, минимизировать их жизненные проблемы; 32,5\% респондентов полагают, что, если бы они все-таки обратились за получением социальных услуг на дому, это не принесло бы ощутимого эффекта в плане повышения качества их жизни.

Вторая проблема свидетельствует о том, что существенная часть респондентов не осведомлена о порядке получения социальных услуг на дому, что позволяет говорить о недостаточной эффективности информационной политики института социальной защиты. С этих позиций отсутствие социального обслуживания можно рассматривать как «социально упущенный шанс» и проявление дискриминации по признаку «осведомленность о социальных услугах». Пожилые люди, часто не имеющие досту-

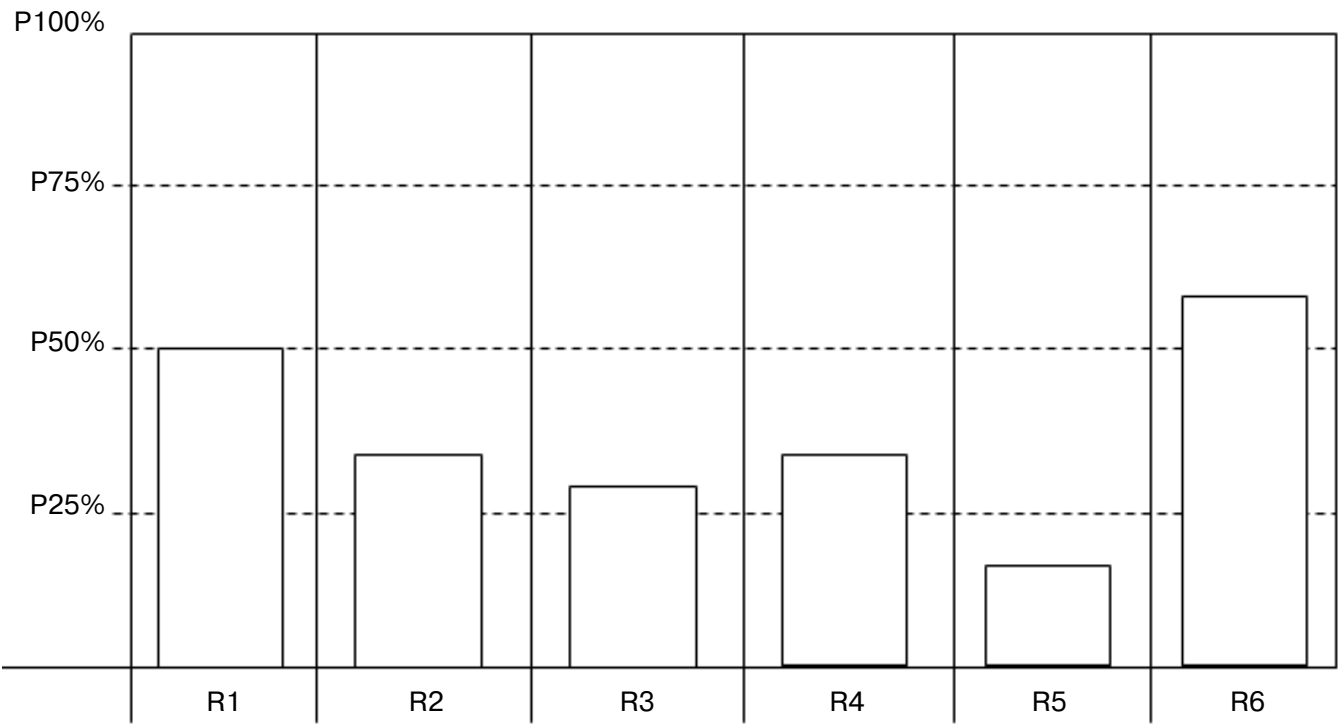

Сочиальные риски респондентов, не получающих сочиильные услуги на дому Social risks faced by respondents who are not receiving in-bome social care:

$\mathrm{P}(\mathrm{N}) \%$ - доля пожилых людей, существенно подверженная социальному риску: R1 - риск материального неблагополучия, R2 - риск ухудшения здоровья, R3 - социальная изолированность, $\mathrm{R} 4$ - утрата родственников, R5 - деформапция поведения, R6 - мошенничество 
па к современным коммуникационным источникам (в частности, сети Интернет), не располагают сведениями о порядке подачи заявления и взаимодействия с социальными работниками, а из-за своих жизненных проблем (состояние здоровья, низкое материальное положение) они часто не могут посетить соответствующий орган для консультации (Сигида, Аукьянова, 2015). Выявлена необходимость совершенствования информационной политики органов социальной защиты в части разъяснения порядка получения социальных услуг на дому. Таким образом, жизненные проблемы пожилых людей имеют локализацию в различных сферах деятельности, при этом они усугубляются несовершенством информационного обеспечения и качеством социальных услуг.

На диаграмме показано соотношение пяти наиболее распространенных видов социальных рисков у пожилых людей, не получающих социальные услуги на дому. На первом месте риск мошенничества (60\%); на втором - риск, связанный с материальным неблагополучием (50\%), на третьем - ухудшения здоровья (35-37\%), на четвертом - утраты родственных связей (34-36\%), на пятом - социальной изолированности, на шестом - деформации норм поведения (20\%).

\section{ЗАКАЮЧЕНИЕ}

Надомное социальное обслуживание как стационарозамещающая форма помощи обеспечивает максимальное приближение социальных услуг к месту проживания клиента, реализацию принципа адресности и доступности. На основании проведенного исследования социальных рисков пожилых людей, не получающих социальные услуги на дому, можно сделать вывод о том, что наиболее распространенными социальными рисками являются риски мошенничества, материального неблагополучия и ухудшения здоровья. В структуре рисков пожилых людей присутствуют также риски утраты родственных связей, социальной изолированности и деформации поведения. У маломобильных пожилых людей меньше возможностей активного участия в социальной жизни и решении жизненных проблем, подверженность социальным рискам у них увеличивается. Выявлены институциональные препятствия, снижающие востребованность надомного социального обслуживания как инструмента минимизации социальных рисков пожилых: недоверие и негативное восприятие института социальной поддержки, а также недостаточная эффективность информационной политики данного института. С этих позиций отсутствие социального обслуживания можно рассматривать как «социально упущенный шанс» и проявление дискриминации по признаку «осведомленность о социальных услугах».

Вышеизложенное убедительно доказывает необходимость совершенствования социального обслуживания как инструмента воздействия на социальные риски пожилых, которое должно стать одним из приоритетных направлений деятельности органов социальной защиты населения, что в конечном счете будет способствовать реализации социальных прав пожилых и, как следствие, повышению качества жизни как совокупности условий, при которых снижаются определенные социальные риски.

\section{СПИСОК АИТЕРАТУРЫ}

Гоман, Е. Ю. (2012) Качество жизни населения в системе функционирования экономики региона : дис. ... канд. экон. наук. Хабаровск. 230 с.

Золотарева, Т. Ф. (2010) Нестационарное социальное обслуживание и качество жизни пожилых людей // Отечественный журнал социальной работы. № 4. С. 88-93. 
Касаркина, Е. Н., Тузова, Ю. А. (2013) Система социальной защиты пожилых людей в России // Актуальные проблемы современной науки в 21 веке : сб. материалов III Междунар. науч.-практ. конф. Махачкала : ООО «Апробация». Ч. 1.190 с. С. 185-187.

Климантова, Г. И., Черняк, Е. М., Щегорцов, А. А. (2014) Методология и методы социологического исследования. М. : Аашков и К․ 256 с.

Колков, В. В. (2011) Модернизация системы социального обслуживания населения // Знание. Понимание. Умение. № 4. С. 94-100.

Корнилова, М. В. (2011) Качество жизни и социальные риски пожилых // Современные исследования социальных проблем (электронный научный журнал). № 3. С. 76.

Сигида, Е. А., Аукьянова, Е. И. (2015) Теория и методология практики медико-социальной работы. М. : Инфра-М. 236 с.

Солнышкина, М. Г. (2005) Социальное обслуживание в системе социальной защиты населения : учеб. пособие. Аубна : Междунар. ун-т природы, о-ва и человека «Аубна». 183 с.

Социальная работа с пожилыми (1995)/ ред.-сост. Т. Е. Аемидова. М. : Ин-т социал. работы. 196 с.

Тимошина, Е. Н. (2012) Социальное обслуживание населения в Москве: социологическая квалиметрия : автореф. дис. ... канд. социол. наук. М. 24 с.

Федеральный закон от 28 декабря 2013 г. № 442-Ф3 «Об основах социального обслуживания граждан в Российской Федерации» [Электронный ресурс] // КонсультантПлюс. URL: http://consultant.ru/document/cons_doc_LAW_166044/ [архивировано в WebCite] (дата обращения: 13.02.2015).

Холостова, Е. И. (2013) Социальная работа с инвалидами. 3-е изд., перераб и доп. М. : Аашков и $\mathrm{K}^{\circ} .240$ с.

Шлыкова, Е. В. (2001) Риск и качество жизни // Риск в социальном пространстве / под ред. А. В. Мозговой. М. : Ин-т социологии РАН. 348 с. С. 221-234.

Щекотин, Е. В. (2011) Рискологическая концепция качества жизни: от потребности к возможности // Теория и практика общественного развития. № 8. С. 67-70.

HelpAge International: Индекс качества жизни пожилых людей в странах мира в 2013 году (2013) [Электронный ресурс] // Центр гуманитарных технологий. 10 октября. URL: http:// gtmarket.ru/news/2013/10/10/6300 [архивировано в WebCite] (дата обращения: 13.02.2015).

Аата поступления: 14.02 .2015 г.

\section{SOCIAL RISKS FOR THE ELDERLY RUSSIANS RECEIVING NO \\ IN-HOME SOCIAL CARE \\ M. G. SOLNYSHKINA, O. A. TYUKIN \\ (MOSCOW UNIVERSITY FOR THE HUMANITIES)}

Against the background of a complicated medical and demographic situation of ageing population, the rising demand for social services, a social category of the elderly is latent and invisible to the modern system of social care at the institutional level. The existing information on their problems, lifestyle and quality of life is insufficient to uphold their rights and ensure their social security.

The problem of improving social services for older people in risk society is an important one for both social science and social work. The riskological concept of the quality of life (as developed by G. P. Petropavlova, E. V. Shlykova, E. V. Shchekotin) has come up with an integrated approach which covers risks, threats and dangers in assessing the quality of life of the elderly.

The research team of the departments of sociology, social work and social medicine at Moscow University for the Humanities (V. V. Kolkov, V. V. Sokolova, E. A. Vorobtsova, S. P. Burtsev) in 2014-2015 completed a survey of social risks for the elderly who are not receiving in-home social care. The respondents to the questionnaire produced by the team were 150 people $(65 \%$ women and $35 \%$ men, aged 64 to 80 ) living in Moscow oblast.

Our study has shown that the most common risks for elderly Russians who are not receiving in-home social services, are those of fraud, material deprivation and ill health. The risks also inclu- 
de loss of family ties, social isolation and behavior issues. We have also identified institutional barriers that reduce the demand for in-home social services as a tool for minimizing social risks for the elderly.

Keywords: social risks, social protection, in-home social care, social services, elderly, quality of life.

\section{REFERENCES}

Goman, E. Yu. (2012) Kachestvo zhizni naseleniia $v$ sisteme funktsionirovaniia ekonomiki regiona [The quality of life of the population within the economic system of the region] : diss. ... Candidate of Economics. Khabarovsk. 230 p. (In Russ.).

Zolotareva, T. F. (2010) Nestatsionarnoe sotsial'noe obsluzhivanie i kachestvo zhizni pozhilykh liudei [Non-stationary social services and quality of life of the elderly]. Otechestvennyi zhurnal sotsial' noi raboty, no. 4, pp. 88-93. (In Russ.).

Kasarkina, E. N. and Tuzova, Yu. A. (2013) Sistema sotsial'noi zashchity pozhilykh liudei v Rossii [The system of social protection of the elderly in Russia]. In: Aktual' nye problemy sovremennoi nauki $v 21$ veke [Topical issues of contemporary science in the 21st century] : Proceedings of the 3rd International research-to-practice conference. Makhachkala, Aprobatsiia LLC. Part 1. 190 p. Pp. 185-187. (In Russ.).

Klimantova, G. I., Cherniak, E. M. and Shchegortsov, A. A. (2014) Metodologiia i metody sotsiologicheskogo issledovaniia [Methodology and methods of social research]. Moscow, Dashkov \& $\mathrm{C}^{\circ}$ Publ. 256 p. (In Russ.).

Kolkov, V. V. (2011) Modernizatsia sistemy sotsial'nogo obsluzhivania naseleniia [Modernization of the public social service system]. Znanie. Ponimanie. Umenie, no. 4, pp. 94-100. (In Russ.).

Kornilova, M. V. (2011) Kachestvo zhizni i sotsial'nye riski pozhilykh [Quality of life and social risks for the elderly]. Sovremennye issledovaniia sotsial' nykb problem (elektronnyi nauchnyi zburnal), no. 3, p. 76. (In Russ.).

Sigida, E. A. and Lukyanova, E. I. (2015) Teoriia i metodologiia praktiki mediko-sotsial'noi raboty [Theory and methodology of the practice of medical social work]. Moscow, Infra-M Publ. 236 p. (In Russ.).

Solnyshkina, M. G. (2005) Sotsial' noe obsluzbivanie v sisteme sotsial' noi zashchity naseleniia [Social services in the system of social protection] : A manual. Dubna, Dubna International University Publ. 183 p. (In Russ.).

Sotsial' naia rabota s pozhilymi [Social work with the elderly] (1995)/ ed. and comp. by T. E. Demidova. Moscow, The Institute of Social Work Publ. 196 p. (In Russ.).

Timoshina, E. N. (2012) Sotsial'noe obsluzhivanie naseleniia v Moskve: sotsiologicheskaia kvalimetriia [Social services in the city of Moscow: Social qualimetry] : abstract of the diss. ... Candidate of Sociology. Moscow. 24 p. (In Russ.).

Federal'nyi zakon ot 28.12.2013 № 442-FZ «Ob osnovakh sotsial'nogo obsluzhivaniia grazhdan v Rossiiskoi Federatsii» [Federal law No. 442-FZ of 28.12.2013 "On the Foundations of Social Services for Citizens of the Russian Federation"]. Konsul'tantPlius [online] Available at: http:// consultant.ru/document/cons_doc_LAW_166044/[archived in WebCite] (accessed 13.02.2015). (In Russ.).

Kholostova, E. I. (2013) Sotsial'naia rabota s invalidami [Social work with disabled people]. 3rd edn., revised and enlarged. Moscow, Dashkov \& $C^{\circ}$ Publ. 240 p. (In Russ.).

Shlykova, E. V. (2001) Risk i kachestvo zhizni [Risk and quality of life]. In: Risk v sotsial' nom prostranstve [Risk in social space] / ed. by A. V. Mozgovaya. Moscow, Publ. House of the Institute of Sociology, RAS. 348 p. Pp. 221-234. (In Russ.).

Shchekotin, E. V. (2011) Riskologicheskaia kontseptsiia kachestva zhizni: ot potrebnosti k vozmozhnosti [The riskological conception of quality of life: From need to possibility]. Teoriia $i$ praktika obshchestvennogo razvitiia, no. 8, pp. 67-70. (In Russ.).

HelpAge International: Indeks kachestva zhizni pozhilykh liudei v stranakh mira v 2013 godu (2013) [HelpAge International: Global AgeWatch Index of the quality of life of the elderly, 2013]. 
Tsentr gumanitarnykb tekbnologii. October 10. [online] Available at: http://gtmarket.ru/news/ 2013/10/10/6300 [archived in WebCite] (accessed 13.02.2015). (In Russ.).

Submission date: 14.02 .2015$.

Солнышкина Марина Георгиевна - доктор социологических наук, профессор, профессор кафедры социологии Московского гуманитарного университета. Адрес: 111395, Россия, г. Москва, ул. Юности, д. 5. Тел.: +7 (499) 374-60-21. Эл. адрес: solny2001@mail.ru

Solnyshkina Marina Georgievna, Doctor of Sociology, Professor, Department of Sociology, Moscow University for the Humanities. Postal address: 5 Yunosti St., 111395 Moscow, Russian Federation. Tel.: +7 (499) 374-60-21. E-mail: solny2001@mail.ru

Тюкин Олег Анатольевич - аспирант кафедры социологии Московского гуманитарного университета, специалист выездной бригады Станции скорой и неотложной медицинской помощи им. А. С. Пучкова г. Москвы, член Российского общества социологов. Адрес: 111395, Россия, г. Москва, ул. Юности, д. 5. Тел.: +7 (499) 374-60-21. Эл. адрес: Le_go@mail.ru. Научный руководитель - А-р социол. наук, проф. М. Г. Солнышкина.

Tyukin Oleg Anatolievich, Postgraduate Student, Department of Sociology, Moscow University for the Humanities; Specialist of a mobile team, A. S. Puchkov Moscow Ambulance and Emergency Medical Care Station; Member, Russian Society of Sociologists. Postal address: 5 Yunosti St., 111395 Moscow, Russian Federation. Tel.: +7 (499) 374-60-21. E-mail: Le_go@mail.ru. Research advisor: Doctor of Sociology, Professor M. G. Solnyshkina. 